\title{
Mechatronics Technology and Transportation Sustainability
}

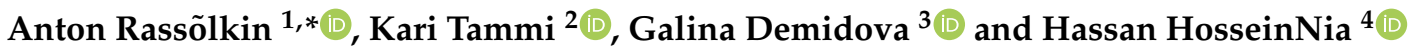 \\ 1 Department of Electrical Power Engineering and Mechatronics, Tallinn University of Technology, \\ Ehitajate Tee 5, 19086 Tallinn, Estonia \\ 2 Department of Mechanical Engineering, Aalto University, 02150 Espoo, Finland; kari.tammi@aalto.fi \\ 3 Faculty of Control Systems and Robotics, ITMO University, Kronverkskiy Prospekt, 49, \\ 197101 Saint Petersburg, Russia; demidova@itmo.ru \\ 4 Department of Precision and Microsystems Engineering, Technical University of Delft, Mekelweg 5, \\ 2628 CD Delft, The Netherlands; S.H.HosseinNiaKani@tudelft.nl \\ * Correspondence: anton.rassolkin@taltech.ee
}

Citation: Rassõlkin, A.; Tammi, K.; Demidova, G.; HosseinNia, H. Mechatronics Technology and Transportation Sustainability. Sustainability 2022, 14, 1671. https://doi.org/10.3390/ su14031671

Received: 24 January 2022 Accepted: 26 January 2022 Published: 31 January 2022

Publisher's Note: MDPI stays neutral with regard to jurisdictional claims in published maps and institutional affiliations.

Copyright: () 2022 by the authors Licensee MDPI, Basel, Switzerland. This article is an open access article distributed under the terms and conditions of the Creative Commons Attribution (CC BY) license (https:// creativecommons.org/licenses/by/ $4.0 /)$.
This editorial introduces a Special Issue (SI) that contains nine chosen articles in Sustainability. The term "mechatronics" was firstly used in 1969 by Tetsuro Mori from Yaskawa Electric Corporation. The word mechatronics is composed of "mecha" from mechanical and the "tronics" from electronics. It includes system design, system integration, electrical machines, power electronics, drives and motion control, vehicle applications, robotics, manufacturing applications, and many other research directions. Since mechatronics was proposed, it has been applied in many industry-related disciplines such as automation and robotics, sensing and control, engineering and manufacturing systems, consumer production and packaging, automotive engineering, agriculture, medical mechatronics, aerospace, etc.

Digitalization of automation and manufacturing systems is a current trend in the industry and is known as Industry 4.0 (I4.0). I4.0 results on upgrade of manufacturing systems and processes and covers the whole lifecycle of the products, from the cradle to the grave (including design, development, prototyping, manufacturing, logistic, use, maintenance, and utilization). In [1], Shirai highlights seven reasons today's companies must apply I4.0 components and novel technologies into enterprise systems: data acquisition and storage, training challenges, testing costs and complexity of AI systems, high regulatory requirements, the high price of failure and change, large state spaces, and cost of talent. Currently, there are many approaches to mechatronics objects control. Linear algorithms are straightforward to employ, and they provide acceptable results in the case of using linearized models. Dynamic control methods based on solving the inverse dynamics problem became widespread, realizability is the main problem of such algorithms' application. Adaptive algorithms provide efficient control in case of parameter and external disturbances uncertainty. However, implementation complexity makes it challenging to use them wide in engineer practice [2], especially in changing environmental conditions [3].

Electrical energy is the most used energy type in the industry and everyday life, while it might be easily converted to light, heat, and mechanical energy. Therefore, research on electrical energy conversion systems opens the discussion in the current SI. The study by Heidari et al. [4] is focused on the most promising type of electrical motor-synchronous reluctance. Due to particular design, this type of electrical machine has less conductive material but is equivalent to induction machine (primarily used in industry) performance. This opening article of the SI disseminates the recent developments in design, modeling, and, more specifically, control of synchronous reluctance motors. The study might be helpful for industries and scholars to opt for a proper control method for trending motordriven systems.

Reducing the raw materials and energy resources touches upon the production of the energy conversion systems as well as the whole industry. Increasing attention is paid to 
digital replicas of various stages of the product lifecycle. Digital representation of products and processes that can provide additional information and services about the product through advanced simulations and predictive algorithms is a trending topic in modern mechatronics. Such paradigm is called digital twins (DTs) and is widely implemented in I4.0 and many other fields, from aerospace to healthcare. The current SI includes two studies on DT technologies. The first research paper by Garg et al. [5] focuses on the DT of industrial robots and suggests using virtual reality for programming and simulation of the robotic cell. The application of modern industrial robots involves different mechatronics subdisciplines, such as communication, energy conversion, control, simulation, etc.; in this case, DT models that assist in the online/remote operation of a unit by creating a 3D digital environment of a real-world configuration is an essential contribution to the field. One of DT's perspective applications is in the automotive industry. The next in the list, the SI contribution by Ibrahim et al. [6], presents an overview of the implementation of DT topology in autonomous electric vehicle (EV) propulsion drive systems. In this contribution, a generic review of main trends in the field of DT developments is supplemented with different simulation technologies comparison and applications analysis.

The notable progress in the electric automotive industry, combined with product innovations, affected broader aspects of mechatronics. EVs' rapid appearance and usage influence the operation of electric power systems. The included research work by Iqbal et al. [7] focuses on estimating time-dependent charging and power quality aspects of grid-connected EVs. The research questions related to the charging demand of the EVs discussed in the contribution by Shabbir et al. [8] extended the scope of the current SI. Sustainable electrical grids of the future include EVs as an essential part of consuming and producing electricity to the grid. Therefore, the current SI further includes the impact of the EVs on low voltage residential networks, as well as more deep studies on electrical grid power quality issues, also by Iqbal et al. [9].

The questions of electrical power grids are not often directly addressed to mechatronics. However, as it was previously defined, mechatronics is a multidisciplinary branch of engineering and, at present, combines mechanical and electronic engineering, but also computer science, control systems, modeling and simulation domains, etc. Combining several energy sources is definitely a multidisciplinary question, and mathematical modeling and simulation of a hybrid system are always challenging for researchers. Therefore, the research questions discussed by Petrochenkov et al. in $[10,11]$ directly address the topic of the SI.

A stable and reliable power grid is essential for I4.0 and the implementation of mechatronics. The research work by Zhukovskiy et al. [12] concludes the SI, in which the authors focused on the management of the workload schedule in order to equalize energy consumption and improve energy-efficient use of equipment. This study is based on the analysis of statistical data for the development of the algorithm for collecting, processing, and planning power consumption data, including all levels of interaction between devices.

This time, the SI focused on different mechatronics aspects that can promote more sustainable technologies in the future. This SI entitled "Mechatronics Technology and Transportation Sustainability" contains nine contributions that were presented as review and research papers by 42 scientists from Estonia, Russia, Turkey, Finland, Pakistan, and Latvia.

Author Contributions: A.R., K.T., G.D., and H.H. have made a substantial, direct, and intellectual contribution to this work and approved it for publication. All authors have read and agreed to the published version of the manuscript.

Funding: The research work by Prof Anton Rassõlkin has been supported by the Estonian Research Council under grant PSG453 "Digital twin for propulsion drive of autonomous electric vehicle". The research work by Prof Kari Tammi has been supported by Machinaide (ITEA3) research project, under the Business Finland grant 3508/31/2019. The research work by Prof Galina Demidova has been partially supported by the Ministry of Science and Higher Education of the Russian Federation, passport of goszadanie no. 2019-0898. 
Institutional Review Board Statement: Not applicable.

Informed Consent Statement: Not applicable.

Data Availability Statement: Not applicable.

Acknowledgments: For this valuable collection of data, the Guest Editors would like to thank all authors who submitted their manuscripts for this Special Issue and congratulate them on publishing their research works with Sustainability. This would not have been possible without the active support of all the Academic Editors and all the anonymous reviewers for their constructive comments and suggestions. Last but not least, we would like to thank the MDPI team for their support of this Special Issue.

Conflicts of Interest: The authors declare no conflict of interest.

\section{References}

1. Charrington, S. Artificial Intelligence for Industrial Application, Cloud Pulse Strategies, Report 2017. 2017. Available online: https:/ / www.cloudpulsestrat.com/go/industrialai (accessed on 20 January 2022).

2. Nemtsev, E.; Zukov, Y. Adaptive neural network control of mechatronics objects. Acta Mech. Autom. 2008, 2, 81-85.

3. Dianov, A.; Anuchin, A. Adaptive maximum torque per ampere control of sensorless permanent magnet motor drives. Energies 2020, 13, 5071. [CrossRef]

4. Heidari, H.; Rassõlkin, A.; Kallaste, A.; Vaimann, T.; Andriushchenko, E.; Belahcen, A.; Lukichev, D.V. A review of synchronous reluctance motor-drive advancements. Sustainability 2021, 13, 729. [CrossRef]

5. Garg, G.; Kuts, V.; Anbarjafari, G. Digital Twin for FANUC Robots: Industrial Robot Programming and Simulation Using Virtual Reality. Sustainability 2021, 13, 10336. [CrossRef]

6. Ibrahim, M.; Rassõlkin, A.; Vaimann, T.; Kallaste, A. Overview on Digital Twin for Autonomous Electrical Vehicles Propulsion Drive System. Sustainability 2022, 14, 601. [CrossRef]

7. Iqbal, M.N.; Kütt, L.; Lehtonen, M.; Millar, R.J.; Püvi, V.; Rassõlkin, A.; Demidova, G.L. Travel activity based stochastic modelling of load and charging state of electric vehicles. Sustainability 2021, 13, 1550. [CrossRef]

8. Shabbir, N.; Kütt, L.; Daniel, K.; Astapov, V.; Raja, H.A.; Iqbal, M.N.; Husev, O. Feasibility Investigation for Residential Battery Sizing Considering EV Charging Demand. Sustainability 2022, 14, 1079. [CrossRef]

9. Iqbal, M.N.; Kütt, L.; Daniel, K.; Asad, B.; Ghahfarokhi, P.S. Estimation of Harmonic Emission of Electric Vehicles and Their Impact on Low Voltage Residential Network. Sustainability 2021, 13, 8551. [CrossRef]

10. Petrochenkov, A.; Romodin, A.; Leyzgold, D.; Kokorev, A.; Kokorev, A.; Lyakhomskii, A.; Perfil'eva, E.; Gagarin, Y.; Shapranov, R.; Brusnitcin, P.; et al. Investigation of the Influence of Gas Turbine Power Stations on the Quality of Electric Energy in the Associated Petroleum Gas Utilization. Sustainability 2022, 14, 299. [CrossRef]

11. Petrochenkov, A.; Romodin, A.; Kazantsev, V.; Sal'nikov, A.; Bochkarev, S.; Gagarin, Y.; Shapranov, R.; Brusnitcin, P. Principles of Imitation for the Loading of the Test Bench for Gas Turbines of Gas Pumping Units, Adequate to Real Conditions. Sustainability 2021, 13, 13678. [CrossRef]

12. Zhukovskiy, Y.L.; Kovalchuk, M.S.; Batueva, D.E.; Senchilo, N.D. Development of an Algorithm for Regulating the Load Schedule of Educational Institutions Based on the Forecast of Electric Consumption within the Framework of Application of the Demand Response. Sustainability 2021, 13, 13801. [CrossRef] 